issues. Copies of this edition can be obtained from the Better Health Centre; telephone (02) 98160452 or fax an order to (02) 98160492.

I am very proud of this report and delighted that its release coincided with the end of my tenure as the Chief Health Officer. This was the second Chief Health Officer's report released during my tenure. The first, in 2002, my first year, confirmed my long-standing view that the population health infrastructure of NSW was world class, and that NSW Health population health practitioners were immensely capable.

The report reflects the health surveillance and intelligence capacity in its broadest aspects. But my observation applies just as firmly to capacity in health protection, health promotion and other aspects of population health planning and service provision. It has been a source of great pride and pleasure that I have been allowed the privilege of contributing to that capacity over the last $3 \frac{1}{2}$ years.

From a personal perspective, the release of the 5 th edition of the Chief Health Officer's report at the end of my time as Chief Health Officer is a wonderful point to mark my transfer to another type of population health activity, back in operational management in the Sydney South West Area Health Service.

I will keenly observe the continuing growth and sophistication of the Chief Health Officer's Report when the 6th edition is published next year. $\mathrm{x}$

\title{
THE NATIONAL PUBLIC HEALTH PERFORMANCE PROJECT: HOW DO WE KNOW WHETHER AUSTRALIAN PUBLIC HEALTH SERVICES ARE PERFORMING?
}

Tim Owen*

Gippsland Regional Office

Victorian Department of Human Services

\section{Louisa Jorm}

Centre for Epidemiology and Research NSW Department of Health

This article describes the Public Health Performance Project, an initiative of the National Public Health Partnership, which set out to develop a set of key performance indicators for public health practice in Australia.

\section{BACKGROUND}

Public health in Australia can boast success stories in many areas, including immunisation, ${ }^{1}$ tobacco control, ${ }^{2,3}$ cervical cancer screening, ${ }^{4}$ prevention of HIV-AIDS, ${ }^{5}$ and prevention of SIDS. ${ }^{6,7}$ However, these successes have not been translated into increased investment in the public health sector. Expenditure on preventive and promotional services, as a proportion of total health expenditure, has remained static over the last 30 years. There has been only a minor increase in the 'community health' category, a classification that includes some public health activities but also a range of personal care services. ${ }^{8}$

One reason for the failure of the public health sector to attract increasing investment may be its lack of clearly articulated measures of performance. The current National Public Health Expenditure Project ${ }^{9}$ and work on returns on investment in public health commissioned by the
Australian Government Department of Health and Ageing ${ }^{10}$ are contributing to the evidence base regarding expenditure on public health and its cost-effectiveness. However, those responsible for public health services lag behind their clinical counterparts in developing and implementing national and local systems for performance monitoring and improvement. ${ }^{11}$

'What gets measured gets done', a corollary of the Hawthorne effect, ${ }^{12}$ describes the increase in internal commitment to performance improvement that can result from external observations of performance. Harnessing this effect relies on using appropriate measures of performance. Although the public health community has made great advances over the last decade in surveillance and reporting of indicators of health status, health outcomes, and determinants of health, ${ }^{3,13}$ these often have major limitations as performance measures. In general, they do not respond quickly to changes in public health practice, and it is difficult to quantify or control for influences outside the control of the health system.

The National Public Health Partnership (NPHP), which was established in 1996, coordinates national public health activities and provides a vehicle through which major initiatives, new directions, and best practice can be assessed and implemented. It operates through the NPHP Group-made up of representatives of federal government, state and territory health departments, the Australian Institute of Health and Welfare (AIHW), and the National Health and Medical Research Council 
(NHMRC)—which reports to health ministers through the Australian Health Ministers' Advisory Council (AHMAC). The NPHP does not fund public health programs directly, although its member organisations do, and it has strong links with the non-government sector through an advisory group.

The memorandum of understanding that underpins the NPHP sets out responsibilities of its members to monitor, evaluate, and report on the performance of public health functions. The Public Health Performance Project represents the most recent stage in the NPHP's ongoing work in this area, and grew out of its involvement in the development of a new National Health Performance Framework, which was led by the National Health Performance Committee (NHPC), a subcommittee of the AHMAC. The framework was designed to support performance monitoring across all sectors of health. ${ }^{14}$ The NHPC uses the framework to: provide a structure for organising and presenting information on health sector performance; support benchmarking for health system improvement; ${ }^{15}$ and provide AHMAC with regular comparative analysis and information on the national health system.

The Public Health Performance Project set out to develop a set of key performance indicators for public health practice in Australia, to report against the framework. Along the way, it explored the context for performance measurement in public health in Australia and some of the key issues and challenges.

\section{THE CONTEXT OF THE PUBLIC HEALTH PERFORMANCE PROJECT}

Current mechanisms for reporting on the performance of public health activities at the national level include the NHPC's annual reports on health sector performance, reports against the Public Health Outcome Funding Agreements (PHOFAs), reporting of indicators developed to support action in the National Health Priority Areas, and reporting as part of government budget-setting processes. The NHPC's 2001 report on health sector performance present 8 measures of health status and outcomes, 11 measures of determinants of health, and 19 indicators of system performance covering acute, community health, general practice, and public health services. ${ }^{15}$ The indicators of system performance for public health services were limited to the areas of immunisation, breast cancer screening, and cervical cancer screening.

PHOFAs are in place for a range of public health programs, including breast and cervical cancer screening, immunisation, drugs, and HIV-AIDS. ${ }^{16}$ A key feature of these PHOFAs is a set of performance indicators, on which states and territories are required to report each year.

Programs for the 7 national health priority areascurrently cardiovascular health, cancer control, mental health, asthma, diabetes mellitus, injury prevention and control, and arthritis and musculoskeletal conditions ${ }^{17,18}$ operate across the spectrum of health care, including the acute and community and public health sectors. Sets of indicators have been developed for these priority areas over the past 6 years, and a subset of these indicators is reported in regular reports of the AIHW. ${ }^{3}$ However, these indicators focus on health outcomes, and only a few are more immediate indicators of system performance.

Varying sets of indicators relating to public health services are also reported as part of the budget-setting processes of both the federal and state governments. Many of these indicators are measures of activity as opposed to performance measures and few are supported by good information systems.

\section{METHODS}

The Public Health Performance Project developed indicators through a 2 -stage consultation process. For the first stage, meetings were convened in each state and territory health department, and with the Australian Government Department of Health and Ageing and the AIHW.

Attendees participated in an indicator rating exercise. They were provided with a list of indicators currently being used in Australia. These were compiled from a range of sources, including PHOFA agreements, budget papers, annual reports, and various national strategies. The indicators were 'mapped' to the NPHP's 9 core functions of public health in Australia (Table 1). These core functions were developed through a Delphi study of public health opinion leaders, ${ }^{19}$ and were endorsed by health ministers in 2000. ${ }^{20}$ Participants were also provided with a set of criteria to use for assessing indicators, based on those proposed by the NHPC. ${ }^{14}$

Participants were asked to rate indicators for inclusion in a national set, on a 5-point scale from lowest to highest priority. Comments on specific indicators were invited, as well as ideas for new indicators.

For the second stage of consultation, a discussion paper summarising the outcomes of the meetings was circulated. ${ }^{21}$ The paper sought comment on a range of issues associated with the development of indicators for public health including:

- how to decide on priorities for performance monitoring;

- structures and processes for reporting and monitoring of indicators;

- classification of public health services for the purpose of performance monitoring;

- utility of the National Health Performance Framework for performance measurement in public health. 
TABLE 1

\section{CORE FUNCTIONS FOR PUBLIC HEALTH PRACTICE IN AUSTRALIA, ENDORSED BY HEALTH MINISTERS, 2000}

- Assess, analyse, and communicate population health needs and community expectations.

- Prevent and control communicable and non-communicable diseases and injuries through risk factor reduction, education, screening, immunisation, and other interventions.

- Promote and support healthy lifestyles and behaviours through action with individuals, families, communities, and wider society.

- Promote, develop, and support healthy public policy including legislation, regulation, and fiscal measures.

- Plan, fund, manage, and evaluate health gain and capacity building programs designed to achieve measurable improvements in health status, and to strengthen skills, competencies, systems and infrastructure.

- Strengthen communities and build social capital through consultation, participation, and empowerment.

- Promote, develop, support and initiate actions that ensure safe and healthy environments.

- Promote, develop and support healthy growth and development throughout all life stages.

- Promote, develop and support actions to improve the health status of Aboriginal and Torres Strait Islander people and other vulnerable groups.

Note: $\quad$ The term 'core functions' refers to the total public health effort and not just to those activities that government public health authorities are responsible for carrying out or funding.

Source: National Public Health Partnership, 2000.20

Comments were also invited on proposed sets of indicators and steps for further development of indicators.

The paper was circulated to all participants in the consultation meetings, members of the NPHP Group, NPHP subcommittees, and other key national committees including the NHPC and National Health Priorities Action Council.

\section{RESULTS}

A total of 152 people participated in the consultation meetings. Participants represented a range of public health program areas, or were specialists in performance measurement in the health sector. Around 350 hard copies of the discussion paper were circulated. Electronic copies were circulated via email and made available on the NPHP website. In all, 36 written responses were received, with

\section{TABLE 2}

INDICATORS RECOMMENDEDTOTHE NATIONAL HEALTH PERFORMANCE COMMITTEE FOR INCLUSION IN REPORTS ON HEALTH SECTOR PERFORMANCE

- Breast cancer screening rates for women within the national target groups

- Cervical screening rates for women within the national target groups

- Number of children fully immunised at 12 months and at 24 months of age

- Percentage of adults aged 65 years and over who received an influenza vaccination for the previous winter

- Percentage of injecting drug users, participating in surveys carried out at needle and syringe programs, who report recent sharing of needle and syringes

- Percentage of teenager smokers who personally purchased their most recent cigarette.

Source: National Public Health Partnership, 2002. ${ }^{2}$ most of these representing the consolidated comments of groups or organisations. ${ }^{21}$

Few of the indicators provided to meeting participants as part of the indicator rating exercise proved to be suitable for inclusion in national indicator sets. Many were indicators of activity (for example, the number of calls received by the Quitline, rather than performance (for example, the proportion of callers to the Quitline that remain smoke-free after 6 months), some represented areas of little investment, and many were too poorly described to be of value. Some of the indicators related to activities that did not occur nationally, or were based on jurisdictionspecific standards or guidelines.

Discussion at the consultation meetings focused on indicators considered to be of value for national reporting and monitoring. Discussion was dominated by suggestions for improving indicators, ideas for new indicators and identifying areas of public health action requiring indicator development.

Two sets of indicators were proposed in the discussion paper and then refined as a result of the comments received. The first set of indicators was proposed for reporting by the NHPC in its future reports on health sector performance (Table 2). ${ }^{21}$ This set includes 3 indicators not previously reported by the NHPC in the areas of influenza immunisation, effectiveness of needle and syringe exchange programs, and cigarette sales to minors. These indicators were subsequently adopted by the NHPC and incorporated in its 2003 report. ${ }^{21}$

The NHPC reports to health ministers on the performance of the whole health system, and hence its reports offer limited space for indicators for each sector. Accordingly, the project proposed that the NPHP, and national and state health agencies, consider mechanisms that monitor and report a broader set of indicators for system performance 
for public health. This broader set is too lengthy to publish here, but the areas of practice covered are summarised in Table $3 .^{22}$ The broader set includes indicators that are more developmental in nature and some indicators that compare the public health sector with other sectors of the health system. Indicators were not limited to areas where data collections are already available, and many of the indicators require new systems for collection and reporting.

Finally, the project identified areas of public health practice for which indicator development is urgently required, as follows:

- primary prevention for non-communicable diseases (in particular public health nutrition, physical activity, injury prevention, and mental health);

- communicable diseases surveillance and response;

- primary prevention for illicit and licit drugs;

- $\quad$ system capacity and infrastructure..$^{22}$

\section{DISCUSSION}

Monitoring performance is an essential part of the cycle of 'Plan-Do-Check-Act' for quality improvement (Figure 1), first developed in the 1920s by Walter Shewhart and popularised later by W. Edwards Deming. ${ }^{23}$ Performance monitoring allows analysis of how public health practice (the 'do' step) is achieving what was planned (the 'plan' step) and is critical to the final 'act' step in the cycle where decisions are made on how to proceed.

Apart from contributing to quality improvement, additional benefits in monitoring performance and reporting national performance measures for public health include:

- increased awareness of the nature and scope of public health services;

- promoting agreement on what constitutes effective public health practice and focusing activity on these best practice approaches;

- improving documentation of the key achievements of public health activity;

- improving the credibility of public health by publicly demonstrating performance against recognised standards.

Despite these benefits, the Public Health Performance Project highlighted several challenges in establishing a mechanism for national monitoring of the performance of public health services in Australia. Perhaps foremost among these was the absence of an overarching national public health strategy, which would identify priorities for performance monitoring. In the United States, the objectives of Healthy people 2010 serve this purpose, and its objectives are supported by a comprehensive strategy for monitoring progress. ${ }^{24,25}$ Among Australian

\section{TABLE 3}

AREAS OF PUBLIC HEALTH PRACTICE COVERED BY INDICATORS PROPOSED FOR MONITORING BY THE NATIONAL PUBLIC HEALTH PARTNERSHIP AND/OR FEDERAL AND STATE HEALTH AGENCIES

- Health protection

- Water fluoridation

- Drinking water quality

- Hepatitis C among injecting drug users

- Timeliness and completeness of notifications of Salmonellosis

- Legionella disease control

- Recreational pool water quality.

- Skin penetration services compliance

- Emergency response preparedness

- Physical activity in older persons for falls prevention

- Antenatal visits

- Quitline calls

- Local public health planning

- Health impact assessments

- System capacity

- Funding for public health research

- Public health expenditure

- Quality assessment programs for surveillance systems

- Health behaviour monitoring

- Population health data reporting

- Public health legislation

- Aboriginal environmental health workers

- Jurisdictional strategic and implementation plans to support national strategies

- Postgraduate public health training

Source: National Public Health Partnership, 2002. ${ }^{21}$

\section{FIGURE 1}

THE PLAN-DO-CHECK-ACT CYCLE

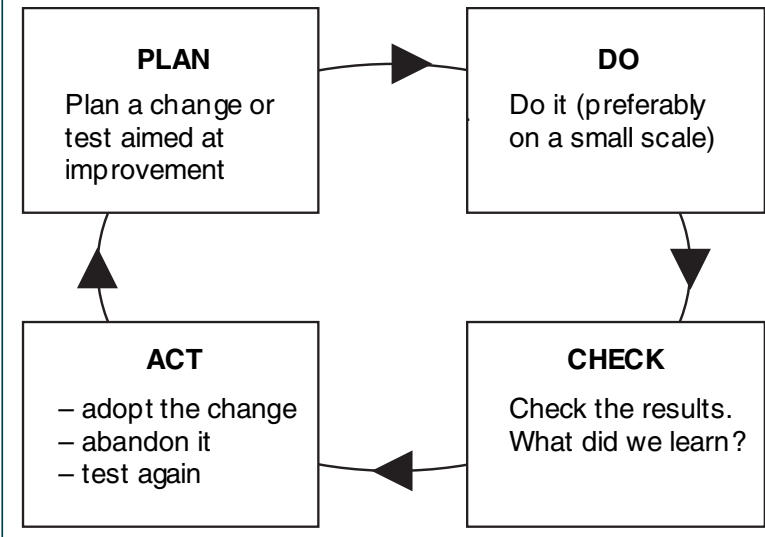

Source: Shewhart, 1931

states, only NSW has developed an overarching public health strategy, ${ }^{26}$ but this is not linked to a system of performance measurement. 
In the absence of a national public health strategy, the project used the NPHP's statement of core functions of public health as a framework for ensuring that indicators were considered for a range of public health activities. ${ }^{20}$ However, the statement does not provide a means for prioritising programs for performance measurement, nor does it set any goals or targets on which to base performance measures. To assist in selecting indicators, the project used a modified version of the NHPC's criteria for selection of health performance indicators. ${ }^{14}$ However, even with uniform criteria, the selection of indicators remained a subjective process.

A second challenge was in defining the scope of the indicators to be included. Many public health activities are carried out by organisations other than government public health agencies. The NPHP's statement of core functions of public health refers to the public health effort, ${ }^{20}$ which is broader than those activities that government public health authorities are responsible for carrying out or funding. The Public Health Performance Project recommended the reporting of indicators of performance for public health activities undertaken by agencies other than government-funded health agencies. This system-wide approach is particularly important in areas such as environmental health, food safety, and health promotion, where a range of other providers are critical to public health service delivery. ${ }^{27}$ However, it could be argued that this makes the sets of indicators less directly relevant to the accountability of those government-funded agencies that have designated responsibility for public health.

A third challenge was in defining system 'performance' as it applies to public health activities. Much public health activity aims to reduce the prevalence of risk factors for ill-health, such as tobacco smoking and physical inactivity. However, indicators that measure determinants of health and the associated health outcomes may not be sensitive to changes in practice, and hence may be poor measures of performance.

The project addressed this by considering the degree to which factors outside the control of the health system influenced the health determinant or outcome in question. To be considered as a performance indicator, an indicator measuring a health determinant or outcome needed to satisfy two criteria. First, modifying the health determinant or outcome should be the specific purpose of a public health activity. Second, factors within the control of the health system should have a dominant influence on the determinant or outcome, or external influences should be able to be estimated and adjusted for. Where these criteria were not met, more immediate indicators of performance were sought.

A final challenge was the identification of appropriate indicators to capture the complexity of public health practice. Indeed, the utility of performance measures in health promotion practice has been challenged because of the difficulty in attributing change to the intervention and difficulty in identifying responsible agencies. ${ }^{28}$ In general, the project identified good performance indicators for public health activities involving intervention delivered to individuals in clinical settings (for example, immunisation, screening), but not for areas of public health practice that rely on community-based activity or are focused on partnerships with other sectors.

Standards-based approaches have potential utility for performance improvement in these areas of practice. In the United States, the Public Health Performance Standards Program provides detailed assessment tools, which are used by state and local public health services to determine compliance with model standards for the United States 10 Essential Services of Public Health. ${ }^{29-31}$ A performance standards approach allows for the assessment of both capacity and process elements of service delivery-sometimes referred to as 'preparedness' - as well as taking a system-wide rather than a program-specific view of public health. One limitation of this approach is its reliance on self-assessment and selfreport of data, which makes it less useful where accountability is a prime purpose for performance measurement.

Recent efforts in the United States have focused on measuring the preparedness of public health services for responding to bio-terrorism and other emergencies, using self-assessment tools and simulation and gaming methods. ${ }^{32-34}$ Such approaches may be applicable in the Australian context, and may also be generalisable to a broad range of public health activities.

\section{CONCLUSIONS}

The Public Health Performance Project developed a set of indicators for national reporting that reflect a wider range of public health activities than those previously reported to Australian health ministers. Much work remains to be done to further improve this set of indicators, and to develop indicator definitions, technical specifications, and in some cases new datasets.

Additionally, there is a pressing need to explore mechanisms for monitoring performance for those public health activities not conducive to performance indicators. Overseas experience suggests that development of model standards and tools for assessing compliance with these, and simulation exercises to assess preparedness, are promising approaches.

The development of an overarching national public health strategy would greatly facilitate performance monitoring of public health activities in Australia. Such a strategy would need to clearly articulate the respective roles and responsibilities of national, state, and local 
agencies - failure to do this has been a major criticism of the United States Healthy people 2010 initiative. ${ }^{35}$ Agreeing on our priorities for what we want public health services in Australia to 'do' would make it easier to define our priorities for what we need to 'check'.

Information about the work of the National Public Health Partnership, including reports from the National Public Health Performance Project, and information about ongoing projects of the National Public Health Information Working Group, can be found online at www.nphp.gov.au.

\section{ACKNOWLEDGMENTS}

The Public Health Performance Project was funded by the National Public Health Partnership. The reference group for the project comprised Louisa Jorm (Chair), Michael Ackland, Peter Woodley, Paul Currall, Paul Jelfs, Gerard Fitzsimmons, Helen Moore, Jackie Steele, Tony Woollacott, Cathy Mead, and Tim Owen (Secretariat). *Tim Owen was a trainee on the NSW Public Health Officer Training Program when he worked on the project.

\section{REFERENCES}

1. McIntyre P, Gidding H, Gilmour R, Lawrence G, Hull B, Horby P, Wang H, Andrews R, Burgess M. Vaccine preventable diseases and vaccination coverage in Australia, 1999 to 2000. Commun Dis Intell 2002 May; Suppl: i-xi, $1-111$.

2. Australian Institute of Health and Welfare and Australasian Association of Cancer Registries. Cancer in Australia 1998. AIHW Catalogue no. CAN 12. Canberra: AIHW, 2001.

3. Australian Institute of Health and Welfare. Australia's health 2002: the eighth biennial health report of the Australian Institute of Health and Welfare. Canberra: AIHW, 2002.

4. Australian Institute of Health and Welfare. Cervical screening in Australia 1997-1998. AIHW Catalogue no. CAN 9. Canberra: AIHW, 2000.

5. National Centre in HIV Epidemiology and Clinical Research. HIV/AIDS, viral hepatitis and sexually transmissible infections in Australia annual surveillance report 2001. Sydney: NCHECR, 2001.

6. Dwyer T, Ponsonby A-L. The decline in SIDS: a success story for epidemiology. Epidemiology 1996; 7: 323-325.

7. Al-Yaman F, Bryant M, Sargeant H. Australia's children: their health and wellbeing 2002. AIHW Catalogue no. PHE 36. Canberra: AIHW, 2002.

8. Deeble J. Resource allocation in public health: an economic approach. Melbourne: National Public Health Partnership, 1999.

9. Australian Institute of Health and Welfare. National public health expenditure report 1999-00 (Health and Welfare Expenditure Series). Canberra: AIHW, 2002.
10. Applied Economics. Returns on investment in public health: an epidemiological and economic analysis. Canberra: Commonwealth Department of Health and Ageing, 2003.

11. Handler A, Issel M, Turnock B. A conceptual framework to measure performance of the public health system. Am J Public Health 2001; 91: 1235-1239.

12. Roethlisberger FJ, Dickson WJ. Management of the worker. Cambridge, MA: Harvard University Press, 1947.

13. Population Health Division. The health of the people of NSW: report of the Chief Health Officer 2002. Sydney: NSW Department of Health, 2002.

14. National Health Performance Committee. National health performance framework report. Brisbane: Queensland Health, 2001.

15. National Health Performance Committee. National report on health sector performance indicators 2001. Brisbane: Queensland Health, 2002.

16. Australian Government Department of Health and Ageing. Public health outcome funding agreements. Available online at www.health.gov.au/pubhlth/about/phofa/phofa.htm. Accessed 7 January 2004.

17. Australian Institute of Health and Welfare and Commonwealth Department of Health and Family Services. First report on national health priority areas 1996. AIHW Catalogue no. PHE 1. Canberra: AIHW and DHFS, 1997.

18. Commonwealth of Australia. National asthma action plan 1999-2002. Canberra: Commonwealth of Australia, 2001.

19. National Public Health Partnership. National Delphi study on public health functions in Australia. Melbourne: NPHP, 2000. Available online at www.dhs.vic.gov.au/nphp/publications/ phpractice/delphi-body.pdf. Accessed 7 January 2004.

20. National Public Health Partnership. Public health practice in Australia today: a statement of core functions. Melbourne: NPHP, 2000. Available online at www.dhs.vic.gov.au/nphp/ publications/phpractice/phprac.pdf. Accessed 7 January 2004.

21. National Health Performance Committee. National report on health sector performance indicators 2003. AIHW cat. No. HWI 78. Canberra: Australian Institute of Health and Welfare, 2004.

22. National Public Health Partnership. Public health performance project: report to the National Public Health Partnership Group. Melbourne: NPHP, 2002. Available online at www.dhs.vic.gov.au/nphp/publications. Accessed 7 January 2004.

23. Shewhart WA. Economic control of quality of manufactured product. New York, NY: Van Nostrand Co Inc, 1931.

24. United States Department of Health and Human Services. Healthy people 2010. 2nd edition. Washington, DC: United States Government Printing Office, 2000.

25. United States Department of Health and Human Services. Tracking healthy people 2010. Washington, DC: United States Government Printing Office, 2000.

26. New South Wales Department of Health. Healthy people 2005: new directions for public health in New South Wales. Sydney: New South Wales Department of Health, 2000.

27. Roper WL, Mays GP. Performance measurement in public health: conceptual and methodological issues in building the science base. J Public Health Manage Pract 2000; 6: 66-77.

28. Buck D, Godfrey C, Morgan A. Performance indicators and health promotion targets. Discussion paper 150, Centre for Health Economics. York: University of York, 1996. 
29. Centers for Disease Control and Prevention. National public health performance standards program: state public health system performance assessmenti. Atlanta, GA: CDC, 2001. Available online at www.phppo.cdc.gov/nphpsp/Documents/ State_v_1_OMB_0920-0557.pdf. Accessed 7 January 2004.

30. Centers for Disease Control and Prevention. National public health performance standards program: local public health system performance assessment instrument. Atlanta, GA: CDC, 2001. Available online at www.phppo.cdc.gov/nphpsp/ Documents/Local_v_1_OMB_0920-0555.pdf. Accessed 7 January 2004.

31. Davis RM. Measuring the performance of public health agencies. Government, like doctors and hospitals, should meet quality standards. $B M J 1999 ; 318: 889-890$.
32. Centers for Disease Control and Prevention. State public health preparedness and response capacity inventory. Version 1.1. Atlanta, GA: CDC, 2002. Available online at www.phppo.cdc.gov/od/inventory/index.asp. Accessed 7 January 2004.

33. Davis LM, Blanchard JC. Are local health responders ready for biological and chemical terrorism? RAND Document No: IP-221-OSD. Santa Monica, CA: RAND Center for Domestic and International Health Security, 2002. Available online at www.rand.org/cgi-bin/Abstracts/ordi/getabbydoc.pl?doc=IP221-OSD. Accessed 7 January 2004.

34. O'Toole T, Mair M, Inglesby TV. Shining light on 'dark winter'. Clin Infect Dis 2002; 34: 972-983.

35. Davis RM. Healthy people 2010: objectives for the United States. BMJ 2000; 320: 818-819.

\section{DEVELOPMENT OF A STANDARDISED REGIONAL REPORT FROM THE NSW HEALTH SURVEY PROGRAM}

\section{Maria Torres \\ NSW Public Health Officer Training Program \\ NSW Department of Health}

\section{David Muscatello}

Program for Enhanced Population Health Infostructure NSW Department of Health

\section{Margo Eyeson-Annan \\ NSW Health Survey Program \\ NSW Department of Health}

The area health services require population health data at the local level, to monitor the health of their populations, plan services, and develop policy. The NSW Health Survey Program is one of the main sources of population health data in New South Wales. In 2002, as part of the program's reporting strategy, a standardised regional report was developed to meet local reporting needs. This article describes the process of developing a template for a standardised form of regional report for each area health service.

\section{BACKGROUND}

NSW Health provides health services through area health services that plan, deliver, and coordinate local health services within their regions. This service model aims to strengthen local commitment to disease prevention and population health. ${ }^{1}$

The Health Survey Program is one of the main sources of population health information in NSW. Since its inception in 1996 until 2001, 2 adult health surveys were conducted, ${ }^{2}$ which had adequate numbers to provide estimates for each area health service. ${ }^{3}$ From 2002, a continuous health survey was implemented, with a yearly sample of approximately 800 adults from each area health service. $^{4}$

Population health information at the local level is necessary for areas to monitor the health of their populations and to support policy development and planning. Areas vary in their capacity to access health survey data and using that data to develop their own reports. Formal and informal consultation with area staff by the Centre for Epidemiology and Research highlighted the need for summaries of local level data to be made available to the areas in both printed and electronic form, ${ }^{5,6}$ with access to downloadable graphics and data tables so that areas could prepare their own reports. Our aim was to develop a standardised regional report for each area that would meet state and local reporting needs.

\section{METHOD}

First, we developed a draft template for a regional report and a questionnaire for consultation. Second, using the draft template and the questionnaire, we consulted with the areas to determine the appropriateness of the regional report to meet their population health information needs. Finally, we used the feedback to finalise the regional report template.

\section{Development of the regional report draft template and questionnaire}

The regional report draft template was developed by considering data available from previous surveys, data limitations, the resources required to produce the reports, ease of interpretation, and previous consultations with 